\title{
Construction of Undergraduates Cultivation Schemes for Vehicle Engineering Based on Life- Cycle Projects
}

\author{
Dong ZHAO \\ School of Mechanical Engineering \\ University of Jinan \\ Jinan, China \\ me_zhaod@ujn.edu.cn \\ Yu'e YANG \\ School of Mechanical Engineering \\ University of Jinan \\ Jinan, China \\ Yuzeng WANG \\ School of Mechanical Engineering \\ University of Jinan \\ Jinan, China
}

\author{
Dongmei CAI \\ School of Mechanical Engineering \\ University of Jinan \\ Jinan, China \\ Yantao AN \\ School of Mechanical Engineering \\ University of Jinan \\ Jinan, China \\ Na LI \\ School of Mechanical Engineering \\ University of Jinan \\ Jinan, China
}

\author{
Luning LIU \\ School of Mechanical Engineering \\ University of Jinan \\ Jinan, China
}

\begin{abstract}
To improve the quality of the cultivation of higher engineers, vehicle engineering professional talent training scheme is constructed based on the life-cycle project - driven personnel training mode. The courses, concentrated practical training and innovation practice will be linked together and form a complete organic knowledge system through the life-cycle project research. In the study of total life-cycle project, the teachers and students are the new inter-subjectivity relationship in which the members have the equal status and work together to complete the project research and the personnel training. Trial application shows that the life-cycle project-driven talent training scheme are very useful for improving the students' practical ability, innovation ability and teamwork spirit.
\end{abstract}

Keywords-project-driven talent training mode; life-cycle project; project-driven talent training scheme; education reform

\section{INTRODUCTION}

Higher engineers are the main force to the social and the country's construction. And their qualities and capacities will directly determine a life-and-death of an enterprise; even affect the core competitiveness of a country. That is to say that the high-quality engineers and technical persons could promote the

This work was financially supported by the Education Reform Project of Shandong Province (2015M042) and Industry-University cooperative education project of the Ministry of Education of the people's republic of China (201602005006) social material civilization and spiritual civilization. In the future for a long period of time, the national competition is the competition of engineers and technical persons in the final. Therefore, the cultivation of high-quality engineers and technical persons must directly affect a country's future. As a result, cultivating of engineers with innovative talent is the core task of higher engineering education in many countries.

However, higher engineering education of the high-quality engineers and technical persons in Chinese colleges has met many problems as below.

\section{A. Emphasis on theory, contempt for practice}

In the traditional higher education or personnel training system, the problem which pay more attention to the basic theoretical knowledge and less attention to practical ability, innovation ability and professional quality training is still in existence. Although in recent years this situation has changed step by step, the effect is not very obvious. In the current higher education process, college teachers still focus on classroom teaching and despise the practical application of knowledge because of time limitation, assessment mechanism and other real conditions. As a result, the more teachers teach, the fewer students learn; the larger knowledge the students are filled, the farther the students are from practical application [1]. The 
problem above lead to very a bad consequence that students have generally believed that learning is just for the examination.

\section{B. Theory, practice and application disconnected from each other}

In the traditional higher education or personnel training system, although course practices are set after part core curriculum, connection between the theoretical teaching and course practices is very loose. You teach yours, I will do mine. Theoretical teaching and courses practice become two parallel lines which have no intersection. More than that, the theoretical teaching and course practices content are less targeted and realtime. Some courses practices haven't changed for decades and have seriously dropped behind the development of related industries. Students' curriculum practice experiences taught in school couldn't be applied in an actual project, let alone the innovation ability training based on problem solving.

\section{Scientific research seriously oppose and disturb teaching}

In the higher education process, college teachers pay less and less attentions on teaching because of time limitation, assessment mechanism and other real conditions. The higher scientific research and academic level the teacher has the less time and energy the teacher use on the undergraduate teaching. Not only those, the university projects tend to very high theoretical research and couldn't support the undergraduate teaching any more.

\section{Systematic and relevance of the teaching system are very poor}

In the higher engineering education system, the undergraduate talents cultivation objectives, standards and contents have been constructed in the talent training system. To achieve this training goal, corresponding courses and practical training have also been set up. But all courses and practical training only target and support the top-level talent training objectives of the higher engineering education. The connections between the courses are so loose that the integral knowledge system of college students couldn't be built after finishing their college education.

Higher engineers with engineering application and innovation are talents between technologists and academics. Therefore, how to cultivate high quality engineering application and innovation talents is a major subject in the face of Chinese higher engineering education [2].

\section{Meaning Of the Life-Cycle Projects Driven TAlent TRAINING MODE}

A real engineer should not sit in classroom, but ought to solve the real problem [3]. In the 1970s, the Worcester Polytechnic Institute developed and implemented the WPI Plan which has a subversive significance to undergraduate education to solve the problems of engineering education which paid more attention to the basic theoretical knowledge and less attention to practical ability. Through the Plan, the students learn how to learn by applying their classroom experiences in projects that challenge them from a proficiency, social, and global perspective [4]. The WPI Plan has changed the traditional rigorous engineering education curriculum system into a flexible and challenging project-based education system, which is committed to cultivating students to use knowledge, solve practical problems, communicate with other people, join in teamwork, transform knowledge into application, make innovation and get other comprehensive ability and quality. The plane will encourage students to learn how to learn [3]. Similar to the WPI Plan, the CDIO INITIATIVE is an innovative educational framework which provides students with an education stressing engineering fundamentals set in the context of Conceiving - Designing - Implementing - Operating (CDIO) of real-world systems and products [5]. The CDIO is an important guarantee for cultivating high-quality engineers.

In order to improve the comprehensive quality and ability of higher engineering and technical personnel, domestic scholars have already tried to put projects in the personnel training system. Mr. Tao Xingzhi's educational theory, which mix teaching, learning and doing into one educational method, took doing the actually project research as a means to improve the "teaching" and "learning" effect. Based on real project research, the students training of the application of innovative is highlighted by colleges [6]. To take cultivating students' practical application ability as the fundamental goal, the teaching content system is built based on the specific practice project. So the students can learn on demand, practice in person, and master the basic content of the course in the completion of the project process [7]. The project-driven teaching model is used in the teaching process. Taking research task or project as the driving force and creating a real research situation, the students can obtain wealth of learning experience and abilities of knowledge application in the research task of project implementation activities [1] [8].

Both domestic and foreign scholars have fully proved and affirmed the outstanding results of the project-driven personnel training model in the high engineering and technical personnel training and actively promote this educational methods in their colleges. Although the project-driven educational methods have already achieved very exciting results in personnel training, the project's function of a bridge, a link and a leader of knowledge is completely ignored. In fact, the life-cycle project-driven talent training mode includes such meaning as below.

\section{A. Life-cycle means that the project can be used through the whole process of higher engineering and technical personnel training in colleges.}

The projects are used through the whole process of the students' college lives. So the first-year college students may meet with and understand the project; the second-year college students contact and join in the project; the juniors will research the project; and the seniors will enhance the project and put them into real application. The projects are used to link up the knowledge of the talent training system into an organic whole. On the basis of life-cycle project, college students will master what knowledge to learn and how to use it after learning. Practice and the learning of the theory will begin at the same time. Practice drives theory learning, and theory learning guides practice. Practice and theory learning will construct a virtuous circle. 
B. Project-driven educational mode can improve the students' practical abilities, innovative abilities, teamwork spirit and other comprehensive qualities.

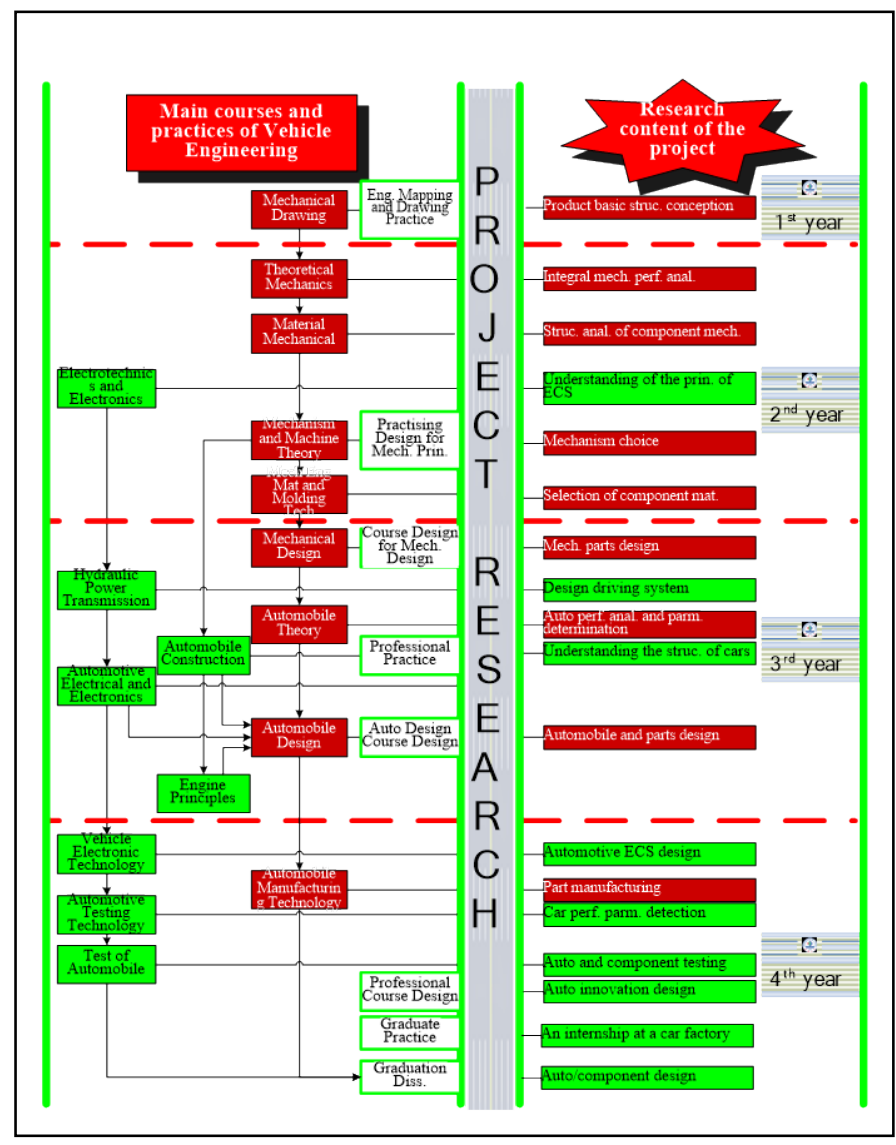

Fig. 1. Main courses and talent training objectives of the program

Based on the actual product and scientific research projects, the students' practical and innovation abilities should be trained according to the normal project research process which includes conceiving, designing, implementing and operating of the projects. The innovative team which is made of different specialties and different grade students will be built according to the need of the project research. Students, teachers are intersubjectivity (Inter-Subjectivity) team members in the innovative team. In the team, the members have the equal status and work together to complete the project.

\section{DeVElopment of Life-CyCle Project - DRIVEN TAlent TRAINING PROGRAM}

Taken the life-cycle project as a link of knowledge and the high-quality personnel training as the goal, vehicle engineering personnel training program is built in our college. Main courses and talent training objectives of the program are shown in Fig.1.

The overall principle of the life-cycle project-driven training program is simply explained as "a main line with three supports". The so-called main line is that the project (product) research process is taken as the main line. Students' practice, innovation and cooperation ability will be cultivated through the whole project (product) research process which includes conceiving, designing, implementing and operating of the real- world products. To support successful development of the personnel training system which take the life-cycle project research as the main line, the project (product) library with a certain degree of complexity must be first established according to the real productions and/or scientific researches. For the future implementation and assessment, each project (product) in the library will be broken down into many subtasks according to courses and practice in the training program. Each sub-task will be assigned a detailed set of research content and assessment objectives. After all the sub-tasks are completed, the entire project will be also finished. All courses and practice in the entire personnel training system will be linked to the project (product). When students graduate from the college, they will get a complete knowledge system, the internalization of knowledge and the abilities to carry out the actual project development rather than many cold and isolated scores.

The so-called three supports refer to curriculum, practice and innovation practice which are the three main important systems that comprise the talent training program. Through the curriculum system, the project (product) R \& D process required basic knowledge, such as drawing, mechanism design; tolerance design and manufacturing process preparation will be taught step by step. And the project (product) has the appropriate sub-task corresponding to each course in the talent training program. So course learning will become a process of project development and implementation, which is inseparable part of the whole knowledge system. Practice is not only an important means of knowledge internalization, but also an important guarantee of the realization and operation of the project. Through the practice, students can use the knowledge to conceive, design, produce, assemble and test the product they designed. The third support is the extracurricular innovation practice. Innovation practice is not only the second internalization of the curriculum system, but also an important guarantee of the training of the students' innovation abilities, innovation consciousness and teamwork abilities. Students use innovative practice to put project (product) in the personnel training system into practical application. Innovative ideas are used to solve problems that students encounter in a project research process or that is derived from the project research. The students' abilities to find and solve problems will be increased step by step based on the innovative practice.

\section{Key Issue in Development of Life-Cycle Project- Driven Talent Training Program}

\section{A. Improve teaching content}

In order to cooperate with the implementation of the lifecycle project-driven personnel training program, the curriculum and practice in the training system should be reformed and changed accordingly. As for courses, the teaching contents are divided and improved according to the project development process, which makes the course contents become the theoretical bases for the development of the project (product). At the same time, taken the project (product) as a vinculum, the course contents will be linked to each other and form an organic whole. In terms of curriculum design practice, traditional invariable contents such as "Mechanism and 
Machine Theory - mechanism design”, “Mechanical Design reducer design” have also changed. The new design contents of the curriculum design practice are different parts of the project (product). The designing scheme will be finished in the practice of Mechanism and Machine Theory; structure and parameter will be chosen in the practice of Mechanical Design; vehicle's structure and parameter will be confirmed in Automobile Design Course Design; a new vehicle innovational design will be created in Professional Course Design; the all structure of the vehicle will be designed in Graduation Dissertation; and the project (product) will be produced and tested in the extracurricular innovative activities at last. In summary, project (product) is used to complete knowledge internalization of the curriculum and practice in the entire personnel training system and to construct the students' practical, innovation and teamwork abilities.

\section{B. Improve the teaching mode of the course}

Traditional "teaching in the classroom, taking the teacher as a protagonist" teaching mode paid too much focus on the knowledge teaching and ignored the internalization of knowledge, highlighted the knowledge and neglected its application. So it is conflicted with the life-cycle project-driven talent cultivation system which takes students' qualities and abilities as purpose. And the traditional teaching mode should not be used any more in the new teaching system. Instead, a new inter-subjectivity relationship of students and teachers will be built and used in the new teaching system.

In the new inter-subjectivity teaching system, there is no choice dilemma of "teacher-based" or "student-centered". Teachers and students in the entire teaching system are equal. The equality of the new inter-subjective teaching system is mainly embodied in the following two aspects:

First, in the classroom teaching, the inversion classroom will be fully used to impart knowledge to students. With the research of the project, courses' knowledge will be decomposed, organized and summarized to a lot of common knowledge points. The knowledge points will be sent to students by network classroom or the MOOCs. Students can finish their self-study according to their own time, knowledge levels and abilities. The classroom time is used to discuss and optimize the project research programs correspond to the course.

Second, in the project research, teachers and students have the equal rights to execute the research, put forward the scheme and express their views. Everyone who participates in the project is a project director and is responsible for the project. Teachers and other students can evaluate, review and give suggestions on the project plan as the "review experts". There is no right or wrong in the project research. The reliability, rationality, feasibility and practicality of projects' functions are verified by tests or market.

\section{The EFFECTIVENESS OF THE PROJECT IMPLEMENTATION}

After the trial execution of a class of students, the projects have shown a very encouraging and beneficial effect. The innovation activity participation of 2013 grade vehicle engineering students of University of Jinan is $86 \%$. The students have received 16 awards at or above the provincial level and 8 patents. $66.7 \%$ students have passed the postgraduate admission scores line. And their acceptance rate is 42.8\%. Among the students who are accepted by postgraduate colleges, two students are admitted to the postgraduate colleges without examination, which is a quarter of the total students. The ration of the graduate without examination is $4.76 \%$, which is 2.8 times as many as the mechanical students. The acceptance rate for graduate students by other colleges is 88 percent. The comprehensive qualities of many students shown in postgraduate and job interviews are highly recognized by other colleges' teachers and companies' owners. The life-cycle project-driven personnel training program has many advantages and will be popularized in the School of Mechanical Engineering.

\section{CONCLUSION}

To improve the quality of cultivation of higher vehicle engineers, a life-cycle project-driven personnel training scheme is constructed in University of Jinan. The projects (products) library is built based on real production requirements and scientific researches to support the development of the projectdriven personnel training scheme. The innovation teams whose members are teachers and students from different grades and specialties are organized to ensure the smooth development of projects (products) research. With the development of projects (products) research, theoretical study and innovation practices will start at the same time. The projects (products) can link up all the knowledge of the talent training scheme into an organic whole. Trial application shows that the life-cycle project-driven talent training scheme are very useful to improve the students' practical ability, innovation ability and teamwork spirit.

\section{ACKNOWLEDGMENT}

The work was financially supported by the Education Reform Project of Shandong Province (2015M042) and Industry-University cooperative education project of the Ministry of Education of the people's republic of China (201602005006).

\section{REFERENCES}

[1] Youyao Liu, Jiang Lin, Huimin Du, et al, "Research and practice on nurturing innovative talents in engineering application," Research in Higher Education of Engineering, vol. 5, pp. 76-81, October 2015.

[2] Zhigang Chen, Xinhai Yang, Jianrong Wu, et al, “On the reform of the five targets' training model for applied and innovative engineering talents in local colleges,” Research in Higher Education of Engineering, vol. 1, pp. 75-80, February 2012.

[3] Tianzuo Yu, Shaoxue Liu and Jupeng Yang, "How to cope with ABET accreditation: a study on the experiences from Worcecter Polytechnic Institute in the U. S. A.,” Research in Higher Education of Engineering, vol. 2, pp. 121-127, February 2015.

[4] The WPI Plan. https://www.wpi.edu/wpi-plan.

[5] CDIO. http://www.cdio.org/

[6] Xin Wang and Min Liao, "Discussion of the design thinking and design ability of students in product design course," Journal of Higher Education, vol. 3, pp. 58-60, September 2010. 